\title{
Re-Thinking the Anthropological and Ethical Foundation of Economics and Business: Human Richness and Capabilities Enhancement
}

Benedetta Giovanola

\begin{abstract}
This article aims at showing the need for a sound ethical and anthropological foundation of economics and business, and argues the importance of a correct understanding of human values and human nature for the sake of economics and of businesses themselves. It is suggested that the ethical-anthropological side of economics and business can be grasped by taking Aristotle's virtue ethics and Amartya Sen's capability approach (CA) as major reference points. We hold that an "Aristotelian economics of virtues", connected with the CA's notion of human richness, can promote the shift to the concept of personhood, and can lead to a more "humanized" business, by fostering human flourishing, the enhancement of human capabilities, and the pursuit of a more humane development for each and every person.
\end{abstract}

KEY WORDS: Amartya Sen, Aristotle, business, capability approach, economics, virtue ethics, Martha Nussbaum, richness, personhood, philosophical anthropology, rationality

A preliminary version of this article was presented at the 15 th "International Symposium on Ethics, Business and Society", held by IESE Business School (Barcelona, May 16-17, 2008).

Benedetta Giovanola, Ph.D. is Researcher in Moral Philosophy and Assistant Professor at the University of Macerata (Italy), where she teaches "Ethics and Economics" and "Ethics and Communication'. Her scientific research mainly focuses on philosophical anthropology and applied ethics, especially social and economic ethics, business ethics and public ethics. She is the recipient of the Helen Potter Award 2005, for her article 'Personhood and Human Richness. Good and Well-Being in the Capability Approach and Beyond', Review of Social Economy 63(2), 2005, 94-107.
Is it possible to provide an ethical and anthropological foundation for economics and business? And, more specifically, is ethics internal to economics and business or is it just a kind of deus ex machina that enters the scene ex post, to "correct" negative externalities? Are the anthropological descriptions and prescriptions about the behavior of economic agents and business actors consistent with the way in which people do behave and ought to behave as human beings? Or is there a conflict between acting as an economic agent (or as a business actor) and acting as a human being?

Leaving these questions in the background, this article argues the need for a sound ethical and anthropological foundation of economics and business, and shows that a correct understanding of human values and human nature is crucial for both economics and businesses themselves. The central conviction is that only an ethical-anthropological underpinning can help us to rise above the major shortcomings of economics and business. The ethical aspect of this underpinning will show the need to question the mainstream notion of economic rationality and to reconnect economic rationality with the ethical dimension of the human being and human fulfillment. The anthropological dimension will be based on the need to criticize the standard notion of homo oeconomicus and to provide a "richer" and more complex idea of human being, and thus of economic agents and business actors too. Both dimensions are strictly interconnected, since the notion of rationality prescribes how agents ought to behave, and such prescriptions, in turn, cannot be separated from an underlying idea of human beings' basic features. 
To date, there have been several important critical investigations aimed at overcoming the flaws of economics and business. With regard to economic theory, very important inquiries in the field of experimental and cognitive economics have sought to highlight the role of cognitive biases at stake in economic choices (Kahneman and Tversky, 1979, 2000; Kahneman et al., 1982; Simon, 1982, 1997, 2000). Their findings undermine some basic assumptions of economic theory, such as its notion of rationality. These considerations also tie in with renewed attention to the importance of the emotional dimension at stake in economic choices (e.g., Slovic et al., 2002). Another criticism of the flaws of economics is motivated by the attempt to re-embed economics in the social context (Hirsch, 1976) and to re-establish the connection between economics and ethics (Sen, 1977, 1985, 1987a, b, 1999a). As we shall see below, these approaches also entail a sharp criticism of the notion of rationality as it is understood in economic theory. Despite their heterogeneity, the different approaches and criticisms are all very important in acknowledging that cognitive, ethical, and social limits are always present when agents (and thus, economic agents too) make a choice.

Similar criticisms have also been turned upon business, analyzing decision-making within organizations. The problem here consists in seeing how individual and collective choices are limited or enhanced by ethical, cognitive, and social elements that play a fundamental role in a company's organization and activity. In this case as well, the central question is whether an organization provides an environment conducive to human growth and fulfillment and whether good corporate policy can encourage and nourish individual growth, by fostering the opportunities for all the employees to develop their talents and potential. These concerns have been explicitly recognized by management studies and form the basis of "humanistic management" (Melé, 2003), whose inquiries tackle the issue of the relationship between business and management, on the one hand, and the human condition on the other.

As will be argued later in this article, some of the most interesting attempts to conceive economics and business in connection with the fostering of human fulfillment assume Aristotle's theories as a starting point (Collins, 1987; Crockett, 2005; Koehn, 1995;
Meikle, 1995, 1996; Van Staveren, 2001, 2007; Vranceanu, 2005).

The most influential attempt to apply an Aristotelian approach in addressing contemporary economic matters and to reconnect economics with ethics is seen in the research carried on by Amartya Sen and Martha Nussbaum, who developed an "Aristotelian-informed" approach, namely, the capability approach (hereafter, CA).

In this article, I will try to show that the CA can offer additional insights into both economics and business and can lead toward the sound, ethical and anthropological foundation of economics and business that we are searching for.

In order to support this claim, the next section pursues a critique of the standard notion of economic rationality and argues in favor of a connection between economic rationality and ethical rationality. Furthermore, this section demonstrates that such a connection is strictly linked with the elaboration of an anthropological model that is much more complex than homo oeconomicus.

The following section suggests that the ethical and anthropological side of economics can be grasped by taking Aristotle's virtue ethics as a major reference point: an Aristotelian perspective on economics namely an "economics of virtues" - is elaborated to show that economics is, and ought to be, about human values and that it can foster human flourishing.

The third section starts by considering the influence of Aristotle on the CA and engages Amartya Sen's version of the approach as a theoretical framework aimed at re-establishing the connection between ethics and economics and at highlighting the importance of a plurality of capabilities to do and to be. This section also dedicates specific attention to Sen's redefinition of the anthropological model underlying economics, by focusing on the notion of anthropological richness. Here it is argued that this notion can provide a foundation for a different anthropological model and can promote the shift from the notion of egoistic individual to the concept of personhood.

The last section applies the "Aristotelian-informed" CA's ethical-anthropological reflection to business to argue for a more "humanized" business and to show that economics and business theory can be compatible with ethics, the fostering of human values and the enhancement of human capabilities. 


\section{Beyond the homo oeconomicus}

One of the major obstacles to the interrelatedness between ethics and economics is linked with economic theory's claim to be as scientific as the natural sciences. According to this claim, economic theory studies human choice behavior under resource constraints; in contrast to ethics, it does not deal directly with ends, but only with the means to realize given ends (Robbins, 1932). ${ }^{1}$

However, as has been rightly noted, the possibility of a purely positive economic inquiry can be questioned, for every inquiry is led by some values even those of scientific inquiry - and some specific values play a fundamental role in determining which questions should be asked (Hausman and McPherson, 2006).

Moreover, it is also important to note that the moral obligations of economic agents can be both a cause and a consequence of important economic phenomena, because on the one side moral obligations can influence the agents' decisions and their behavior in economic processes, and on the other hand economic phenomena can have an impact on agents' motivational structure, by enhancing or limiting their "moral" preferences; at the same time, economic phenomena are influenced by the way they are described and evaluated by economic agents and economists (Hausman and McPherson, 2006, p. 306 f.). Still, human behavior (including economic behavior) is influenced by a wide range of normative and ethical considerations.

However, how is it possible to draw this conclusion? In order to answer this question, we need to focus on the notion of rationality, which is a central issue of economics. Now, what does rationality mean in economics?

According to mainstream economic theory, rationality consists in maximizing one's utility function (which is expressed in terms of individual preferences hierarchically ranked) under a resource constraint. Thus, rationality means exclusively "economic rationality," which is the ground of the influential rational choice theory ${ }^{2}$ and concerns the relationship between preferences and choices: a choice is rational if it is determined by a rational set of preferences, and the set of preferences is defined within the contexts of utility theory. This means that an individual is rational if, and only if, his or her preferences can be represented by ordinal utility functions, and his or her choices maximize utility (Hausman and McPherson, 2006).

It is thus clear that economic theory does not offer any specific prescription regarding the nature, content, or value of preferences, whose rationality is assured by two purely formal conditions: completeness, according to which it is possible to express a preference or a rational indifference among all the possible alternatives; and transitivity, according to which, if option A is preferred to B and option B is preferred to $\mathrm{C}$, then option $\mathrm{A}$ is preferred to $\mathrm{C}$ too; this means that preferences for $\mathrm{A}, \mathrm{B}$, and $\mathrm{C}$ are not on the same level, but are hierarchically ranked. These formal conditions have also been defined in terms of "internal consistency of choice", which is at the basis of the so-called "weak" form of rationality (Sen, 1977).

Such an understanding of rationality, however, does entail some serious flaws. In particular, the possibility of ranking all the preferences in a hierarchic and transitive way presupposes perfect knowledge of all the possible alternatives to make a rational choice, that is, a choice that maximizes utility. The requirement of perfect knowledge, together with that of self-interest maximization, defines the so-called "strong" form of rationality (Sen, 1977), which leads to very serious shortcomings. In fact, its fundamental assumptions are particularly problematic, especially if we analyze choice behavior in conditions of risk or uncertainty, since our rationality, far from being unlimited, is a bounded rationality, ${ }^{3}$ as Simon $(1982,1997,2000)$ has shown in an excellent way.

Furthermore, research on cognitive biases in experimental economics and experimental game theory has shown that human behavior frequently deviates from rational choice theory. ${ }^{4}$ This is why Kahneman and Tversky (1979, 2000) and Kahneman et al. (1982) argued for the need to abandon "folk psychology" - on which the standard notion of economic rationality relies - and to direct attention to the framing of decisions, which means to highlight the psychological complexity of human choices (see also Slovic et al., 2002).

Despite some limits, these inquiries - often with a contribution from the neurosciences (hence, the branch of neuroeconomics) - pursue a critique and a redefinition of the monistic conception of rationality 
underlying mainstream economics, and aim at overcoming some flaws and biases of rational choice theory and neoclassical economics.

The biases of the standard notion of economic rationality are also connected with the formal character of its prerequisites. In particular, although the prerequisites of rationality are formal and no assumption about the content of preferences is made, economics cannot be "value-neutral", as it claims. In other words, economics, even though it seeks neutrality to ethics, ends up by endorsing a specific ethical position. In fact, indifference to the content of preferences implies an ethical subjectivism and ethical relativism, according to which the identification and choice of values are relative to each and every individual, and individual preferences exclusively depend on the individual's ethics, whatever those may be. This is based on the conviction that individual well-being is the only element that counts and that, even if different individuals have different accounts of well-being and different preferences, all the sets of preferences are on a par for the functioning of economic processes. To put it another way, even if nothing is stated about the content of preferences, this principle of "minimal benevolence" (Hausman and McPherson, 2006, p. 65) according to which, other conditions being equal, it is morally good that people enhance their own wellbeing and satisfy their own preferences - rests upon a view of economic agents as utility maximizers and self-interested individuals (Hausman and McPherson, 2006, p. 64). Such a view leads to the Homo Oeconomicus model to which a great part of contemporary economic theory refers. In brief, we can say that homo oeconomicus is an exclusively selfinterested individual, seeking to maximize selfinterest and perfectly conscious of the consequences of his or her choices.

From these considerations, it follows that a redefinition of the neoclassical notion of economic rationality is fundamental, and also involves a reconsideration of the anthropological model proper to (neoclassical) economic theory, according to which human beings would be oriented to selfinterest achievement and to preference maximization (and, then, to the improvement of their wellbeing or utility) under resource constraints. ${ }^{5}$ An inquiry into the missing ethical capabilities in the standard notion of economic rationality is thus needed, and requires a revision of the anthropological model underlying economics.

\section{Toward an "economics of virtue"}

If the standard notion of economic rationality entails some deficiencies that have an ethical dimension, and if it lacks an adequate ethics, which ethical theory then can fill the gap? The suggestion of this article is to take a major ethical tradition - Aristotle's virtue ethics - as a reference point and to focus on a contemporary approach that has been widely influenced by Aristotle's thought: the capability approach (CA). ${ }^{6}$ In general, the CA can be defined as a theory of human development and quality of life, or as "a broad normative framework for the evaluation and assessment of individual well-being and social arrangements" (Robeyns, 2005, p. 94), the core characteristic of which is the focus on peoples' "capabilities to do and to be" (Sen, 1987a, b, 1993, 1999a), namely, what people are effectively capable to do and to be (whereas people's effective states of doing and being are called functionings).

Actually it is important to point out that - as will be clarified later in this article - the CA is neither a mere reformulation of Aristotelian theories, nor a simple neo-Aristotelian approach, but rather, an approach that seems to be compatible with Aristotle's reflection on ethics (Van Staveren, 2007, p. 31) and economics; this is why the CA could be defined as an "Aristotelian-informed" approach that does, however, entail its own peculiarities and shows influences from other theories that in some cases let it deviate from a "pure" Aristotelian underpinning.

More specifically, Aristotle provides us with a "richer" conceptual framework for analyzing the relationship between economics (and business) and ethics. Relying on an Aristotelian framework, the CA deepens the analysis of these connections and is the theory that most prominently highlights the importance of a plurality of capabilities to do and to be, and captures the Aristotelian focus on the plurality of life dimensions to flourish. In general, both Aristotle and the CA argue the relationship between ethics and economics by highlighting the crucial role of the ethical and evaluative dimension in economic processes. Economics then, cannot do without the consideration of ethical assumptions and outcomes, 
because such assumptions and outcomes deeply influence economic behavior. This ethical dimension can be grasped by putting forward the role of human values, which go far beyond merely economic ones and can re-orient economic activity beyond the pursuit of mere self-interest, toward the pursuit of human fulfillment. This is why both Aristotle and the CA share the attempt to show that economics is, and ought to be about human values.

Let us start with Aristotle: it is interesting to note that an Aristotelian perspective is at the basis of some recent attempts to show the intrinsic connection between ethics, economics, and human flourishing (Meikle, 1995; Van Staveren, 2001, 2007). According to these approaches, Aristotle is credited with giving a central role to four ethical capabilities (moral commitment, emotion, deliberation, and human interaction), which are neglected by mainstream economic theory (van Staveren, 2001). Highlighting these ethical capabilities also entails a revision of the anthropological model underlying economics.

Aristotle's theory indeed represents a compelling starting point and a fruitful theoretical horizon for establishing the close link between ethics and economics, and showing that the latter is not an end in itself, but a means to achieve further ends that are extra-economic, and concerned more generally about "human flourishing" (eudaimonia) and the "good life" (Pol, I, 9, 1257b, 40-1258a, 2). Human flourishing or eudaimonia defines the "human good" - that is, the good which is proper to the human being - and "implies the possession and the use of one's mature powers over a considerable period of time", "the fulfillment of the natural capacities of the human species" (Cooper, 1975, p. 89, n. 1).

According to Aristotle, economics (oikonomike) has a functional, not finalistic, nature and it is a necessary, but not sufficient, instrument for attaining a good life. Good life, in fact, even though it cannot do without the possession of material goods, does not exhaust itself in such a material component, but depends rather on a plurality of human dimensions. Wealth, Aristotle states, is "a set of instruments" (Pol, I, 8, 1256b, 37-38) and bears its value "only if it is 'useful', that is, in function of something else" (NE, I, 5, 1096a, 5-7). Analogously, crematistics (chrematistike), or the acquisition of goods, is "according to nature" only to the extent to which it aims at obtaining "the goods necessary to live and useful to the community of the State or the family" (Pol, I, 8, 1256b, 29-30), but it degenerates into unnatural crematistics if it overcomes the limit of necessity and becomes an end unto itself. Thus, the acquisition of goods (crematistics) and the art of managing them (economics) are important, but only insofar as they maintain their functional nature. In contrast, they become "against nature" if they are assumed as an end.

An ideal of self-moderation is thus at stake in Aristotle's understanding of economic affairs: on the one hand, (material) wealth is to be evaluated by how it contributes to a good and flourishing life; on the other hand, only by working out the constitutive elements of a good and flourishing life can we identify what to demand from the economy.

The good life is a virtuous life: according to Aristotle, virtues are those dispositions "for which a person becomes good and well performing its function" (NE, II, 6, 1106a, 22-24): virtues are real and actual traits of the character and thus contribute to the formation of a good character. More precisely, Aristotle states that virtue is "a disposition concerning choice, consisting in a medietas [a Mean] in relation to us" (NE, II, 6, 1106b, 36-11076a, 1): such a Mean, found as it is between two extremes, is evidently of a qualitative nature and, from the point of view of good, it represents an optimum, or an excellence. The virtuous action is indeed teleologically oriented toward excellence, i.e., toward the formation of a good character and the fulfillment of a good life (i.e., human flourishing or eudaimonia): therefore any specific human activity - and thus economic activity too - ought to be oriented by the reference to this telos (eudaimonia, indeed). The way in which virtue should be pursued is indicated by deliberation, that is, a voluntary act of human will, a real choice, rather than the determinate outcome of an algorithm, depending on external constraints (van Staveren, 2001, p. 8).

In conclusion, according to an Aristotelian perspective, economic affairs are not free-standing; consequently, sound economic theories (and practices) cannot be defined by merely quantitative parameters but need to be assessed by qualitative criteria, the most important being the opportunity, for each agent, to realize his or her own potential and thus to fulfill himself or herself in a flourishing 
life. In other words, endorsing an Aristotelian perspective makes it possible to think of economics as means toward human flourishing and excellence.

These considerations have important counterparts from a philosophical-anthropological perspective. In fact, whereas neoclassical economics depicts human beings as "disembodied and disembedded individualists who only have subjective preferences", the Aristotelian framework implies that there is "a shared though differentiated human nature", namely, "a shared human tendency to become virtuous and not a virtuous human nature" of an essentialist kind (van Staveren, 2001, p. 10).

The above concept means that human beings are also considered capable of acquiring virtues that perfect them. As a matter of fact, since actions cannot be separated from the people who perform them and depend, first, on the agent's motivational structure even more than on "exogenous enforcement" mechanisms, and since there exists a mutual relation between actions (and choices) and character (and preferences), it is possible to argue that preferences (and thus character) are subject to a change in time.

\section{Human richness and capabilities enhancement}

At this juncture, the concept of capability enters the scene. In fact, according to a capability perspective, human beings are not a priori entities: they fulfill and actualize themselves through their agency, namely through their capabilities to do and to be. But what is a capability? According to Sen, the term "capability" means substantive freedom, i.e., a real opportunity to be and to do something, which best expresses the positive side of freedom (Sen, 1999a). This is why Sen argues that positive freedom (freedom to achieve something) can be defined in terms of a person's capability (Sen, 1999a, p. 25) or, in other words, it can be seen in the form of "individual capabilities to do things a person has reason to value" (Sen, 1999a, p. 56). In other words, capability is the substantive freedom to achieve alternative functioning combinations (Sen, 1999a, p. 79): functionings, in their turn, are states of doing and being.

According to Sen, the identification of fundamental capabilities is context-dependent: this is why he rejects any attempt of "fixing a cemented list of capabilities that is seen as being absolutely complete [...] and totally fixed", since "pure theory cannot 'freeze' a list of capabilities for all societies for all time to come" (Sen, 2005a, p. 158). ${ }^{7}$ His idea is that the identification of fundamental capabilities should rest on "public reasoning", which is defined as a democratic procedure aimed at creating the space for shared evaluations (Sen, 2005a, p. 163). At the same time, however, he expresses the need for an "ethical objectivity", which entails respect for individual plural evaluations and the importance of developing "views from a "certain distance"" (Sen, 2004, p. 161, 2005a, p. 160 f.).

In this regard, it is interesting to note that Sen, in advocating such an ethical objectivity, specifically refers to Aristotle and argues the need for an "Aristotelian ethics" based on the "fulfilment of valuable functionings and the capability to create and enjoy these functionings" (Sen, 2006, p. 52). Even from these brief considerations, it is thus clear that the CA embraces some major Aristotelian ideas: in particular, the CA recovers the founding elements of Aristotle's ethical theory, his idea of the good as interconnected with human capabilities and functionings, his focus on the multi-dimensional and dynamic character of human beings, as well as his idea that human beings flourish and fulfill human nature in particular ways that vary from person to person, even if they all strive toward human flourishing (eudemonia). The comparison could go so far as to consider the notion of capability itself as corresponding to Aristotle's idea of dynamis (Sen, 1993, p. 126). Furthermore, as has been rightly noted, "the valuational exercise put forward by the CA has strong Aristotelian roots" (Comim, 2008, p. 164), and this has also been recognized by Nussbaum and Sen (1988, p. 315).

It is thus evident that even if Aristotle is not the only one to exert an influence on the CA, his influence is crucial and has been explicitly recognized by Nussbaum (1986, 1988, 1990, 1993, 1995, 2000) and later by Sen as well (1987a, 2006; see also Nussbaum and Sen, 1988, p. 308 ff.). ${ }^{8}$ In particular, with regard to economics, Sen recognizes in Aristotle the founder of the "ethical origin" of economics, which he seeks to restore, in contrast to the prevailing "engineering" approach (Sen, 1987a). 
In order to do develop his ethical approach to economics, Sen pursues his well-known criticism of mainstream economic rationality and its underlying "narrow view" of the person (the homo oeconomicus model), according to which human beings are seen merely as the "location of their respective utilities" (Sen and Williams, 1982). In opposition, he highlights the motivational complexity of every human choice (and thus of economic choice too), and explores a plurality of capabilities to do and to be (actions and ways of being) as the basis of human behavior and human identity. In particular, he demonstrates that, if people behaved in the way rational choice theory prescribes, they would act like "rational fools" (Sen, 1977).

The redefinition of (economic) rationality (on which the actions of economic agents rely) is thus strictly linked with more sophisticated assumptions about the notion of the agent usually assumed by economic theory as a strictly "economic agent". This is why Sen's earlier works sought to criticize the standard notion of the economic agent as homo oeconomicus. Human beings, he argued, are much more sophisticated than the way economic theory depicts them (Sen, 1977) and human actions and decisions are not only driven by self-interest, but also by sympathy and commitment. In particular, commitment is strictly connected with a person's moral principles and can also diverge from personal wellbeing: it can modify a person's goals and his or her rational choice, by giving importance to other people's aims that cannot be included in the pursuit of personal interest (Sen, 2005b, p. 7). These considerations clarify Sen's redefinition of (economic) rationality: by recognizing the importance of commitment and moral obligations, (economic) rationality can no longer be conceived as mere selfinterest maximization, and the rational economic agent can no longer be conceived as a mere selfish utility maximizer. In particular, rationality includes a critical scrutiny of values and objectives that underlie every behavior (Sen, 2002, p. 53 f.): its major function therefore is of an ethical-normative kind, and is strictly connected with the capability to think and act with wisdom. In other words, rationality, according to Sen, concerns the identification of fundamental human values and objectives and their concrete fulfillment through practice. Furthermore, the importance of commitment and the scrutiny of a person's values and objectives are also connected with the notion of personal identity, which is defined by the way a person considers himself or herself, according to his or her values and objectives. Personal identity however, is strictly linked to social identity, a person's capability to identify himself or herself with other persons, to consider himself or herself in relation to others. ${ }^{9}$ This is why in his later works, Sen no longer focuses exclusively on the identity of the economic agent, but rather on the identity of agents, human beings that perform actions in relation with other human beings (Sen, 1999b, 2007).

Throughout his reflection, Sen tackles both ethical and philosophical-anthropological issues at the basis of economics: in particular, both his criticism of neoclassical (utilitarian) economic theory and his redefinition of rationality have an ethical foundation and are grounded in the need to overcome a narrow anthropological view and to show the anthropological complexity of human beings. However, what does anthropological complexity mean? In order to answer this question, we need to develop a twofold line of thought.

First, the CA attributes high importance to human diversity. This implies respect for difference and plurality, since each person differs from everyone else, and there is a plurality of (different) persons. However, such a respect for difference and plurality does not degrade into a form of subjectivism, nor into radical individualism. On the lines of Aristotle, the CA assumes that there are important spheres of shared human experience (grounding experiences) that define fundamental capabilities, which ought to be preserved and fulfilled in a virtuous life (Nussbaum, 1993). There are also, nevertheless, differences and plurality among individuals that need to be preserved. Thus, we might argue, at the level of humanity in general, there are universal capabilities, but personal (and particular) ways of developing them. As one might notice, the acknowledgment of the diversity among human beings is also consistent with the CA's understanding of human flourishing as influenced by Aristotle. In fact, as we have seen, according to Aristotle, human beings flourish and fulfill human nature in particular ways that vary from person to person. CA stresses this point, arguing that flourishing depends on the development of our capabilities, which are always personal. 
There is also a second level of analysis, which refers to the concept of a person. At this level another kind of diversity becomes evident, the diversity within human beings that we might call intrinsic diversity. In fact, diversity is also seen in internal characteristics within every person, as shown by the notion of capability itself: people have various aspirations, desires, preferences and, above all, various capabilities. The misleading utilitarian "narrow view" of human beings consists exactly in overlooking their intrinsic pluralism and in reducing them to one function, and moreover to a merely quantitative one, that of utility maximization. Similar to the attention to diversity among individuals, the attention to human complexity and intrinsic diversity is also consistent with the CA's Aristotelian notion of flourishing, which depends on different life-dimensions and not on just one function: this means that human beings are complex entities that are characterized by an intrinsic anthropological multidimensionality as well as the interconnection of different dimensions.

This point has important implications for the way economics should be understood. In fact, Sen distinguishes between the idea of being "well-off" and that of being "well", or of having "well-being". The idea of being "well-off" conveys opulence and refers to a person's command over exterior things, whereas the idea of being "well", or of having "well-being", refers to something in a person that (s)he achieves. The latter expresses a distinctively personal quality lacking in the former (Sen, 1985). We can say that in the second case, the person can flourish, whereas in the first, (s)he can only maximize his or her utility and enjoy opulence. But flourishing, as we have seen, means realizing the highest Good in a virtuous life in the highly important context of social relations. How, then, can human beings flourish? Of course, not by focusing on quantitative-economical wealth (opulence), but rather on an internal qualitative richness, which goes beyond the concept of opulence; only such an intrinsic and qualitative constitutive plurality can foster self-realization and flourishing. In order to further develop this point, we can speak of an "anthropological constitutive plurality", in which different dimensions and capabilities are connected (Giovanola, 2005). ${ }^{10}$

Now, the notion that best expresses the "anthropological constitutive plurality" and makes the basic assumptions of the CA's idea of personhood explicit is the notion of human richness, which seems a very central issue assumed by, and implicit in, the major ideas of the CA itself: why human richness, and what does it mean?

The notion of human richness has been widely discussed by a thinker who, along with Aristotle, exerted great influence on the CA: Karl Marx, in his first writings. The Marxian influence on the CA has been explicitly acknowledged by both Sen (1980, 1985, 1987a) and Nussbaum (1988, 2000): in particular, they refer to Marx's focus on positive freedom (Sen, 1987a) and to his Aristotelian understanding of human functionings (Nussbaum, 2000), which are said to be closely linked to the notion of capability (Nussbaum, 2000; Sen, 1980, 1985, 1999a).

Now, Marx's interpretation of the notion of richness is intrinsically connected with his idea of positive freedom and his understanding of human functionings, and can be grasped through a capability perspective. In fact, in his Manuscripts, Marx argues that instead of considering richness and poverty as political economy does, one should rather pay attention to the "rich human being". ${ }^{11}$ According to Marx, such a "rich" human being needs both plurality of human dimensions and relationships with other human beings to fulfill his own potential, that is, to become really human, and thus social. On one hand, human beings should be capable of, i.e., free to, fulfill their own potential and to function in different ways. On the other hand, both poverty and richness should gain a "human, and therefore social meaning": in other words, the highest richness for each human being is other human beings, and such a richness is felt in the form of a need (Marx, 1844, Third Manuscript). This means that self-realization can fully succeed only if the social and relational dimension of personhood is recognized, since every person is intrinsically relational. In other words, through their relational dimension, human beings can become "richer," since their relationships with others increase their identity. This recognition, far from turning into something like a communitarian identity, highlights the importance of the interpersonal relationality and means that interpersonal relations can change each one's personal identity. This element is particularly crucial in the CA too and is strictly linked to the role of commitment and to the 
interconnection between personal identity and social identity.

These considerations introduce another very important feature expressed by the notion of anthropological richness and implicit in the CA, the dynamic dimension of personhood. The CA's intrinsic plurality, and its focus on the dimension of "being able to do and to be" shows the importance of a dynamic (and never ending) process in which people constitute their identity, and pursue human flourishing.

This also means that the way we are can be changed by developing our capabilities. This is also evident from the CA's re-interpretation of the Aristotelian Greek concept of eudaimonia: according to the CA, in fact, human flourishing consists in a complex self-realization, but the basic idea is that there are other possibilities than the one I am realizing now: there is neither a fixed nor a firm form of the self. In this regard, the concept of richness seems to express in the best way this openness to new possibilities of the self.

In short, the notion of anthropological richness is able to express the following dimensions of identity: the intrinsic plurality of capabilities and life dimensions, which we could define as the intrapersonal relationality of the self; the interpersonal relationality, namely, the socio-relational dimension of the self, according to which human beings are intrinsically "relational," so that each one "needs" to be in relation with the others; and the dynamic dimension of the self, according to which identity is a dynamic notion, for human flourishing is an ongoing and never definitively defined process. This is why the notion of human richness, as noted above, can serve as the ultimate foundation for CA's concept of personhood (Giovanola, 2005).

\section{Toward a more "humanized" business}

If we attempt to apply the ethical-anthropological conception outlined above to business and management, the latter would undergo such substantial changes that they would depart in no small measure from their prevailing assumptions. In general, the ethical-anthropological inquiry that has been developed in the previous sections aims at reconnecting business theory and practice with the fostering of human values and the enhancement of human capabilities. The question now is whether rational economic activity in business (usually identified by the pursuit of self-interest and profit) is compatible with ethical activity, and whether the pursuit of efficiency is compatible with the fostering of human fulfilment. The analysis of these ethical issues also requires a deep reflection on the vision of the human being at the basis of business, although most prevailing business theories lack an adequate anthropological investigation.

On the first point, we can state that with regard to business, recognizing the role of ethics means affirming that "if ethics is not also acknowledged as valid in itself and desirable by all members of a firm, including its managers and owners, it will not be convincing and effective" (Koslowski, 2008, p. 36). In other words, it is necessary to show that ethics is not external, but internal to business behavior, since it does play a fundamental role in the structure of preferences and desires of business actors. In this regard, the Aristotelian framework and the CA can offer us fruitful elements, by highlighting the role of human values in economic choices and by pointing out the mutual relation between actions (and choices) and character (and preferences).

On the second point, both Aristotle and the CA help us develop a different anthropological model on which business can rely. Thanks to their reflection, we can develop more human models in business and a "humanized" company strategy (Andrews, 1989), and carry out more humanistic management, that is "management that emphasizes the human condition and is oriented to the development of human virtue, in all its forms, to its fullest extent" (Melé, 2003, p. 79).

It is not by chance that some of the most interesting attempts to conceive business in connection with the fostering of human fulfillment assume Aristotle's theories as a starting point (Collins, 1987; Crockett, 2005; Koehn, 1995; Meikle, 1996; Vranceanu, 2005): in this context, some scholars have developed an "Aristotelian approach to business" to talk about corporations and organizations in general (Solomon, 1992, 2004). The basic idea is that, according to Aristotle, one has to think of oneself as a member of the larger community - the Polis for him, the corporation, the society, and so on for us - and strive to excel, to bring out what is best 
in ourselves and our shared enterprise. What is best in us - our virtues - are, in turn. defined by that larger community, and therefore no ultimate antagonism exists between individual self-interest and the greater public good (Solomon, 2004). In this view, the corporation is seen as a community, and is characterized by the search for excellence, the importance of integrity and sound judgment. All of this can lead to a more cooperative and humane vision of business, where the virtues of honesty, trust, fairness, and compassion become central in the competitive business world, and moral courage is needed (Solomon, 1992). According to this view, a company should be considered as a community of persons rather than a mere instrument for profit, could foster the development of human virtues and therefore take into account everyone's need to grow as a person through human virtues (Melé, 2003, p. 85).

However, even if the most important constituents of every organization are human beings, we rarely find a definition of business theory that directly refers to individuals, or that is "human-based". The CA can help us to fill this gap and to think of business as "human-based," by focusing on the constitutive elements of personhood, that a more "human" business should promote. As we have seen, the CA explicitly recognizes the fundamental role of a sound anthropological foundation, but it does not explore in any substantive sense the nature of the corporate economy, nor does it specifically address business matters. Nonetheless, in recent years, the CA has been further developed in an organizational context by Cornelius and Gagnon (1999), Cornelius et al. (2008), and Vogt (2005). In particular, it has been used to analyze the ethical aspects of participative governance (Collier and Esteban, 1999) and to understand equality in the workplace (Cornelius, 2002; Cornelius and Gagnon, 1999, 2000, 2002, 2004).

Still, its application to business could be particularly fruitful to link business with the fostering of human values and the promotion of authentically human capabilities. If we apply the main features of anthropological richness to business and management, the latter will be intrinsically aimed at enhancing people's capabilities (intrapersonal relationality of personhood), at promoting genuine interpersonal relationship in the workplace (interpersonal relationality of personhood), at letting employees grow as a person through their practice (dynamic dimension of personhood), finally, at contributing to the pursuit of human fulfillment and a good life.

\section{Conclusion}

Assuming Aristotle's thought and the CA as theoretical framework can provide a sound ethical and anthropological foundation of business. Such a foundation is particularly necessary and urgent nowadays, when economic activity and business have ever greater structural effects on human beings, the significance of which go far beyond economics. In fact, such effects can also concern extra-economic areas, such as the constitution of personal identity and interpersonal relationships. For example, one of the greatest social costs of irresponsible companies is the production of socioeconomic uncertainty and, in particular, the inability of a growing number of individuals to project into the future, with the development, also in their private life, of short-term engagements, and intermitting family and love relations (Boltanski and Chiapello, 1999, pp. 503507), with further impact at the level of personality (Palmade, 2003).

A reform, then, is needed, especially because contemporary developments of capitalism have compromised the reproduction of those values and "anthropological types" that allowed the working of capitalism itself at its origins, and have substituted them by more and more quantitative values (Castoriadis, 1996). Now, if we want to avoid reducing human beings to a corollary of economy, an ethical and anthropological foundation is needed, because even the economy, as we have seen, is not independent from people's lives and, at a more radical level, affects values, identity, and interpersonal relationships. This is why we need more human models in economics and business. In this regard, the CA, with its attempt to re-establish the (often perceived as paradoxical) interconnection between ethics and economics and with its inquiry into "richer" anthropological models, can serve as an adequate theoretical framework.

In other words, the CA helps us to think of economics and business as means for human flourishing, 
rather than as ends in themselves. The reason lies in the CA's focus on capability enhancement and its elaboration of an ethical-anthropological underpinning for economics. The core of this underpinning is the notion of human richness, which makes it possible to overcome the emphasis on self-interest and personal well-being as utility maximization, and to promote the shift from the notion of the egoistic (economic) individual, to the concept of personhood. This ultimately refers to CA's understanding of the concept of human being as a normative concept, and to its focus on the notion of a "common humanity" (Nussbaum, 1993). According to this framework, business practices would be able to foster human fulfillment and the enhancement of individuals' capabilities, and could contribute to the pursuit of a more humane development for each and every person. ${ }^{12}$

\section{Notes}

1. Such a position is systematized in a view of economics as a positive or descriptive science, which takes natural sciences as a model and differs from normative economics (which aims at evaluating economic processes and outcomes, and formulates prescriptive judgments on what ought to be done to realize an optimal level of welfare - hence the name welfare economics).

2. Rational choice theory is a framework for understanding and often modeling social and economic behavior. Since a long time, it has been the dominant paradigm in economics, but in recent decades it has become more widely used in other disciplines such as sociology, political science, philosophy, and anthropology. Rational choice theory usually assumes the viewpoint of the individual (methodological individualism) and rests upon the idea that individuals choose the best action according to stable preference functions and constraints facing them.

3. The term "bounded rationality" indicates that perfectly rational decisions are often not feasible, due to the finite computational resources available for making them; it is used to designate rational choice that takes into account the cognitive limitations of both knowledge and cognitive capacity, and is concerned with the ways in which the actual decision-making process influences decisions.

4. Also deprivation and adaptation can make human behaviour deviate from rational choice theory's assumptions. Such issues, however, even if they are very important, cannot be addressed in this article.
5. Actually, mainstream economics is not only concerned with the issue of individual well-being, but also with the definition and measurement of social welfare, which is defined by the principle of Pareto-optimality. The latter, however, identifies optimality with efficiency (a Pareto-optimal state of affairs defines an efficient allocation of resources) and generates serious problems, the principal one being the impossibility of tackling equity reasons and solving the trade-off between efficiency and equity.

6. The CA approach has been developed by the Indian economist A. Sen and the American philosopher M. Nussbaum. However, the focus here will be on A. Sen's version of CA, rather than on Nussbaum's, for the former develops greater detail on the ethical-economic side of CA, whilst the latter deals more specifically with the philosophical-political side. Even if Sen and Nussbaum are the main exponents of the CA, there are various (and in many cases important) differences between them, which, however, do not fall within the purview of this article. For a detailed analysis of similarities and differences between Sen and Nussbaum, see Robeyns (2005) and Giovanola (2005, 2007).

7. The difference between Sen and Nussbaum on this point is clear. In fact, the American philosopher has defined a list of fundamental human capabilities (see Nussbaum, 2000, 2006).

8. On the Aristotelian influence on Nussbaum's CA, see Alexander (2008), especially Chap. 3 entitled "Aristotle and Nussbaum's Hybrid Theory of Capabilities" (pp. 125-146). Among the major thinkers and scholars who have influenced the CA, a fundamental role is played by John Rawls. Rawlsian influence is especially evident in Sen's attempt to extend Rawls' focus on primary goods in a "non-fetishist" direction (Sen, 1980) and in his criticism of Utilitarianism (Sen, 1999a; Sen and Williams, 1982); Rawlsian influence on Nussbaum is evident throughout her works and culminates in Nussbaum (2006), where she discusses both similarities and differences between her capability-informed philosophical-political approach and the Rawlsian theory of justice. Rawls' influence is particularly important since it is strictly connected with the CA's version of liberalism and its criticism of utilitarianism, which play a fundamental role in both Sen's and Nussbaum's theory (on the tension between CA's liberalism and the Aristotelian influence, see Giovanola, 2007). Influence on the CA has also been exerted by Karl Marx (through both Sen and Nussbaum), Kant, Grotius, the Stoic tradition (that especially influenced Nussbaum), A. Smith, K. Arrow and, more in general, the exponents of social choice theory (who especially influenced Sen). Of course, a detailed inquiry into such influences cannot be carried 
out in this article. Nonetheless it is important to point them out for the sake of clarity.

9. For further inquiry into Sen's concept of identity, see Sen (1999b); for an interpretation of Sen's arguments, see Davis (2003, pp. 150-166), and Giovanola (2007). For an overview on the role of interpersonal relationships in economics, see Gui and Sudgen (2005).

10. It is worth mentioning that Sen adopts the expression "constitutive plurality", although he uses it mainly as a feature of evaluation. In fact, he distinguishes a "competitive" from a "constitutive" plurality, arguing that the former regards different views that are alternative to one another, whereas the latter describes a kind of "intrinsic diversity" internal to a certain view, embracing different, though not mutually exclusive, aspects (Sen, 1987b).

11. Marx uses the German term "Reichtum" (Marx, 1844, Drittes Manuskript, Sect. 2. Privateigentum und Kommunismus), which is usually translated as "wealth". However, since Marx aims at giving it a different meaning from the prevailing political-economic one, here I will translate it with " "richness".

12. Human development is an expression used in CA, and the United Nations Human Development Reports take the CA as their theoretical framework.

\section{Acknowledgments}

The author would like to thank all the participants of the 15th "International Symposium on Ethics, Business and Society" (IESE Business School, Barcelona, May 16-17, 2008) and especially Claus Dierksmeier, for their helpful comments. In addition, the author would like to thank Francesco Totaro, Gianluca Busilacchi, Julian Rode, and the anonymous referees for their thoughtful comments on earlier versions. Special thanks are due to Domènec Melé for his helpful advice and comments on several issues discussed in this article. Thanks are also due to Sheila Beatty for her linguistic edition of the text.

\section{References}

Alexander, J. M.: 2008, Capabilities and Social Justice. The Political Philosophy of Amartya Sen and Martha Nussbaum (Ashgate, Aldershot).

Andrews, K. (ed.): 1989, Ethics in Practice: Managing the Moral Corporation (Harvard Business School Press, Boston).

Aristotle: 1980, Nichomachean Ethics (NE), translated by D. Ross, revised by J. L. Ackrill and J. O. Urmson (Oxford University Press, Oxford).
Aristotle: 1988, in S. Everson (ed.), Politics (Pol) (Cambridge University Press, Cambridge).

Boltanski, L. and È. Chiapello: 1999, Le nouvel esprit du capitalisme (Gallimard, Paris).

Castoriadis, C.: 1996, Les carrefours du labyrinthe, vol. IV, La montée de l'insignifiance (Seuil, Paris).

Collier, J. and R. Esteban: 1999, 'Governance in the Participative Organisation: Freedom, Creativity and Ethics', Journal of Business Ethics 21(2/3), 173-188.

Collins, D.: 1987, 'Aristotle and Business', Journal of Business Ethics 6, 567-572.

Comim, F.: 2008, 'Measuring Capabilities', in F. Comim, M. Qizilbash and S. Alkire (eds.), The Capability Approach: Concepts, Measures and Applications (Cambridge University Press, Cambridge/New York), pp. 157-200.

Cooper, J. M.: 1975, Reason and Human Good in Aristotle (Harvard University Press, Cambridge, MA).

Cornelius, N.: 2002, Building Workplace Equality: Ethics, Diversity and Inclusion (Thomson International Business Press, London).

Cornelius, N. and S. Gagnon: 1999, 'From Ethics by Proxy to Ethics in Action: New Approaches to Understanding Ethics and HRM', Business Ethics: A European Review 8(4), 225-235.

Cornelius, N. and S. Gagnon: 2000, 'Re-Examining Workplace Equality: The Capabilities Approach', Human Resource Management Journal 10(4), 68-87.

Cornelius, N. and S. Gagnon: 2002, 'From Equal Opportunities to Managing Diversity to Capabilities: A New Theory of Workplace Equality?', in N. Cornelius (ed.), Equality, Diversity and Inclusion in Work Organizations (Thomson International Business Press, London), pp. 13-58.

Cornelius, N. and S. Gagnon: 2004, 'Still Bearing the Mark of Cain? Ethics and Inequality Measurement', Business Ethics: A European Review 13(1), 26-40.

Cornelius, N., M. Todres, S. Janjuha-Jivraj, A. Woods and J. Wallace: 2008, 'Corporate Social Responsibility and the Social Enterprise', Journal of Business Ethics 81(2), 355-370.

Crockett, C.: 2005, 'The Cultural Paradigm of Virtue', Journal of Business Ethics 62(2), 191-208.

Davis, J. B.: 2003, The Theory of the Individual in Economics (Routledge, London).

Giovanola, B.: 2005, 'Personhood and Human Richness. Good and Well-Being in the Capability Approach and Beyond', Review of Social Economy 63(2), 249-267.

Giovanola, B.: 2007, 'Sulla capacità di essere felici: riflessioni su ricchezza, benessere e libertà a partire dal capability approach', Meridiana 56, 83-104.

Gui, B. and R. Sudgen (eds.): 2005, Economics and Social Interaction. Accounting for Interpersonal Relations (Cambridge University Press, Cambridge). 
Hausman, D. M. and M. S. McPherson: 2006, Economic Analysis, Moral Philosophy, and Public Policy, 2nd edition of Economic Analysis and Moral Philosophy (Cambridge University Press, Cambridge/New York).

Hirsch, F.: 1976, Social Limits to Growth (Harvard University Press, Cambridge, MA).

Kahneman, D., P. Slovic and A. Tversky (eds.): 1982, Judgment Under Uncertainty: Heuristics and Biases (Cambridge University Press, New York).

Kahneman, D. and A. Tversky: 1979, 'Prospect Theory: An Analysis of Decision Under Risk', Econometrica 47(2), 263-291.

Kahneman, D. and A. Tversky (eds.): 2000, Choices, Values and Frames (Cambridge University Press, Cambridge).

Koehn, D.: 1995, 'A Role for Virtue Ethics in the Analysis of Business Practice', Business Ethics Quarterly 5(3), 533-539.

Koslowski, P.: 2008, 'Some Principles of Ethical Economy', in C. Cowton and M. Haase (eds.), Trends in Business and Economic Ethics (Springer, Berlin/Heidelberg), pp. 31-70.

Marx, K.: 1844, 'Ökonomisch-Philosophische Manüskripte aus dem Jahre 1844', in Marx-Engels Werke (MEW), Ergänzungsband I (Dietz Verlag, Berlin, 1968), pp. 465-588.

Meikle, S.: 1995, Aristotle's Economic Thought (Clarendon, Oxford).

Meikle, S.: 1996, 'Aristotle on Business', The Classical Quarterly, New Series 46(1), 138-151.

Melé, D.: 2003, 'The Challenge of Humanistic Management', Journal of Business Ethics 44, 77-88.

Nussbaum, M.: 1986, The Fragility of Goodness: Luck and Ethics in Greek Tragedy and Philosophy (Cambridge University Press, Cambridge).

Nussbaum, M.: 1988, 'Nature, Function and Capability: Aristotle on Political Distribution', Oxford Studies in Ancient Philosophy Supplement, 145-184.

Nussbaum, M.: 1990, 'Aristotelian Social Democracy', in R. B. Douglass, G. Mara and H. Richardson (eds.), Liberalism and the Good (Routledge, New York), pp. 203-252.

Nussbaum, M.: 1993, 'Non-Relative Virtues: An Aristotelian Approach', in M. Nussbaum and A. Sen (eds.), The Quality of Life (Clarendon Press, Oxford), pp. 242-269.

Nussbaum, M.: 1995, 'Aristotle on Human Nature and the Foundations of Ethics', in J. E. J. Altham and R. Harrison (eds.), World Mind and Ethics. Essays on the Ethical Philosophy of Bernard Williams (Cambridge University Press, Cambridge), pp. 86-131.

Nussbaum, M.: 2000, Women and Human Development. The Capabilities Approach (Cambridge University Press, Cambridge).
Nussbaum, M.: 2006, Frontiers of Justice: Disability, Nationality, Species Membership (Harvard University Press, Cambridge, MA).

Nussbaum, M. and A. Sen: 1988, 'Internal Criticism and Indian Rationalist Traditions', in M. Krausz (ed.), Relativism: Interpretation and Confrontation (University of Notre Dame Press, Notre Dame, IN).

Palmade, J. (ed.): 2003, L'incertitude comme norme (Puf, Paris).

Robbins, L.: 1932, An Essay on the Nature and Significance of Economic Science (Mac Millan, London).

Robeyns, I.: 2005, 'The Capability Approach - A Theoretical Survey', Journal of Human Development 6(1), 93-114.

Sen, A.: 1977, 'Rational Fools', Philosophy and Public Affairs 6, 317-344.

Sen, A.: 1980, 'Equality of What', in A. Sen (ed.), Choice, Welfare and Measurement (Blackwell, Oxford), pp. 353369.

Sen, A.: 1985, 'Well-Being, Agency, and Freedom. The Dewey Lectures 1984', The Journal of Philosophy 82, 169-221.

Sen, A.: 1987a, On Ethics and Economics (Blackwell, Oxford).

Sen, A.: 1987b, The Standard of Living: The Tanner Lectures 1985 (Cambridge University Press, Cambridge).

Sen, A.: 1993, 'Capability and Well-Being', in M. Nussbaum and A. Sen (eds.), The Quality of Life (Clarendon Press, Oxford), pp. 30-53.

Sen, A.: 1999a, Development as Freedom (Oxford University Press, Oxford).

Sen, A.: 1999b, Reason Before Identity (Oxford University Press, Oxford).

Sen, A.: 2002, Rationality and Freedom (Harvard University Press, Cambridge, MA).

Sen, A.: 2004, 'Elements of a Theory of Human Rights', Philosophy and Public Affairs 32(4), 315-356.

Sen, A.: 2005a, 'Human Rights and Capabilities', Journal of Human Development 6(2), 151-166.

Sen, A.: 2005b, 'Why Exactly is Commitment Important for Rationality?', Economics and Philosophy 21(1), 5-14.

Sen, A.: 2006, 'La felicità è importante ma altre cose lo sono di più', in L. Bruni and P. L. Porta (eds.), Felicità e libertà. Economia e benessere in prospettiva relazionale (Guerini e Associati, Milano), pp. 39-58.

Sen, A.: 2007, Identity and Violence. The Illusion of Destiny (Norton, New York).

Sen, A. and B. Williams (eds.): 1982, Utilitarianism and Beyond (Cambridge University Press, Cambridge).

Simon, H. A.: 1982, Models of Bounded Rationality, vols. 1, 2 (MIT Press, Cambridge, MA).

Simon, H. A.: 1997, Models of Bounded Rationality, Vol. 3 (MIT Press, Cambridge, MA). 
Simon, H. A.: 2000, 'Bounded Rationality in Social Sciences: Today and Tomorrow', Mind E Society 1(1), 25-41.

Slovic, P., M. Finucane, E. Peters and D. MacGregor: 2002, 'The Affect Heuristic', in T. Gilovich, D. Griffin and D. Kahneman (eds.), Heuristic and Biases: The Psychology of Intuitive Thought (Cambridge University Press, Cambridge/New York), pp. 397-420.

Solomon, R.: 1992, Ethics and Excellence: Cooperation and Integrity in Business (Oxford University Press, Oxford).

Solomon, R.: 2004, 'Aristotle, Ethics and Business Organizations', Organization Studies 25(6), 1021-1043.

Van Staveren, I.: 2001, The Values of Economics. An Aristotelian Perspective (Routledge, London/New York).
Van Staveren, I.: 2007, 'Beyond Utilitarianism and Deontology: Ethics in Economics', Review of Political Economy 19(1), 21-35.

Vogt, C. P.: 2005, 'Maximizing Human Potential: Capabilities Theory and the Professional Work Environment', Journal of Business Ethics 58, 111-123.

Vranceanu, R.: 2005, 'The Ethical Dimension of Economic Choices', Business Ethics: A European Review 14(2), 94-107.

Department of Philosophy and Human Sciences, University of Macerata, Via Garibaldi 20, 62100 Macerata, Italy E-mail:giovanola@unimc.it 